\title{
Informing Processes and Models: A Core Course in IS Curriculum
}

\section{Dimitar Christozov American University in Bulgaria, Blagoevgrad, Bulgaria}

\author{
dgc@aubg.bg
}

\author{
Stoyan Denchev and \\ Stefka Toleva-Stoimenova \\ State University of Library Science \\ and Information Technologies, \\ Sofia, Bulgaria
}

\begin{abstract}
Human-technology interaction is an essential issue to the field of Information Systems. The fast growing quantity of available data shifts emphasize to data presentation in a way to increase informing effectiveness and efficiency. To build such information services, the designers have to obtain broad understanding on the concepts, models and processes of informing science. The paper shares the experience of introducing a course "Informing Processes and Models" in SULSIT (State University of Library Studies and Information Technologies) as a core course for Information Brokerage major and elective for the two other IS related majors - Information Technology and Information Security. The experience obtained so far shows that the understanding of the informing science concepts, processes and different models improves IS design and implementation quality.
\end{abstract}

Ke ywords: Information; Information Systems; Informing; Informing Systems

\section{Introduction}

During the last twenty years, since the Internet has been launched, the amount of information used in all areas of human activity increases rapidly. From one side this is caused by the easiness of information availability, and from other side the globalization, supported by Internet, increases the needs for broader and comprehensive information to everybody on the marketplace. Such development challenged human ability for information processing and challenged professionals engaged in design, implementation and maintenance of information systems. To address the growing market demand for professionals, trained to serve as mediators between the ocean of information and the users of information, the State University of Library Studies and Information technologies introduced a major, Information Brokerage (see Christozov, Denchev, Toleva-

Material published as part of this publication, either on-line or in print, is copy righted by the Informing Science Institute. Permission to make digital or paper copy of part or all of these works for personal or classroom use is granted without fee provided that the copies are not made or distributed for profit or commercial advantage AND that copies 1) bear this notice in full and 2) give the full citation on the first page. It is permissible to abstract these works so long as cred it is given. To copy in all other cases or to republish or to post on a server or to redistribute to lists requires specific permission and payment of a fee. Contact Publisher@InformingScience.org to request redistribution permission.
Stoimenova, \& Rasheva-Yordanova, 2008). Information brokers need to posses knowledge and skills to process information, not only to solve their own problems, but to serve their clients. The skills of dealing with information in a productive way from one side depends on the skills of using information technology, but from the other side depends on how clients acquire information and explore it to buildoperational know $1-$ 
edge. To train knowledge and skills to this second part of necessary abilities, a course "Informing Processes and Models" was designed as a core course in Information Brokerage major. University graduates, from all disciplines, expect to work in an environment where information and information systems play an important, even critical, role in their everyday business and life, this course was open for students in two other related to information systems majors - Information Technology and Information Security.

This paper shares the experience obtained in training the course of Informing Processes and Models. The first section introduces the curriculum framework - the Information Brokerage major in which this course is an essential part. Second section is dedicated to the content and teaching approach adopted in the course. The third section addresses the students learning objectives and students' outcome assessment. The fourth section discusses the impact of this course on students from other disciplines. In Conclusion, we shares our vision on the impact of introducing such a content to students in different, related to information systems, disciplines; and share difficulties and problems the teaching team faces in designing and implementing this course.

\section{The Major of Information Brokerage}

The dilemma "sinking in information and be ing not enough informed", characterize the last twenty years. There are two major factors supporting the need of establishing proper education of professionals trained to inform clients, professionally educated information mediators - Information Brokers.

The first one is advancement of information technologies and their overall impact. In the last years all facets of human life have changed significantly by information and communication technologies, making them unavoidable.

The second major factor is globalization of the world economy, with two basic consequences:

- In everyday business, one has to make proper and rational decisions, based on complete, correct and reliable information. Mutually available access to information makes clients almost as informed as sellers regarding the prices, properties and other conditions related to the products. This results in increasing competition. Even very small busineses operate now on the global market, and the information about the global markets become essential for surviving.

- The amount of available information, which flooded our life, is challenged by the limit of human ability to process it in timely manner. It is almost impossible to dedicate enough attention to comprehend possible effects of different activity paths.

Effectiveness and efficiency in dealing with information becomes one of the most important factors for success in any sphere of human activities and at the same time exploring information becomes more complex, requiring special knowledge and skill in dealing with wide variety of techniques. The efforts for developing own expertise in the field of information research often conflicts with the demand of other needs of particular profession. This especially affects small and medium size enterprises, because the large companies are able to establish their own bodies of professionals providing information services.

With growing understanding of the need for proper use of information the demand to satisfy these needs grows. This may result in using external services and consultants by small and medium size enterprises. The role of these consultants is to serve as mediators between the "flood of information" and the client. Thus we may define the two kinds of services of Information Brokers - as independent consultants, and as information service experts. The market demand for such experts is growing and it is expected to continue growing. The US Department of Labor, in its forecast for fastest growing occupations (see http://www.bls.gov/emp/emptab21.htm), placed the profes- 
sion of network and data analysts on the top of the list with more than 50\% increase of the positions in the next 10 years.

The Information Brokerage curriculum is designed to produce graduates equipped with know $1-$ edge and skills to serve as information mediators (see Christozov et al., 2008). To be a successful professional Information Broker, an individual one need to posses knowledge in the following areas:

\section{Information Searching and Delivery}

The following areas of expertise affect effective and efficient search of information:

- The volume of accessible resources. Through Internet one can get free access to vast volume of information. Using different technologies to deal with highamount of data is an essential skill.

- Not free accessible sources. The most valuable information is delivered via sources, which do not provide free access. Also, sometimes the most precious information is available as 'old fashion' hard copy or it is possessed solely by human experts. The three categories of skills to access such information sources include communication skills, dealing with paper-based sources and with sources with restricted access.

- Good understanding about the tools used by search engines (e.g. organization of indexes) helps in writing queries, which improves the quality of the retrieved sample.

- The diversity of sources, which impacts the quality of information, requires expertise allowing assessment about reliability and trustfulness of informationand expertise for its verification.

\section{Efficient Use of IT}

Skills of efficient use of Information technology are essential nowadays for everybody, but this is especially important for professionals dealing with information.

\section{Analysis, Structuring and Creation of Secondary Information}

To inform clients, simple information retrieval is not sufficient. Retrieved information needs to be analyzed, structured and presented to clients in the best form to serve their needs in effective and efficient way.

Statistical knowledge, as well as know ledge about data analysis drawn from other disciplines, such as machine learning, artificial intelligence, etc., is essential for discovering the pieces of valuable information from available data. Additionally, presentation of information requires skills of using presentational techniques and also psychological know ledge, needed to serve human clients. Achieving expertise in this broad area is critical for a successful Information Broker.

\section{Consulting and Business}

One of the essential roles an Information Broker is to provide services as independent consultant. Students need to gain information and to develop skills in performing consulting activities in a professional manner, which includes writing offers, negotiating, contracting, planning, reporting, etc. Skills of running a business such as accounting and management are also quite important. Additionally, the majority of problems that Information Brokers will face in their professional career are business related. This places understanding about the business and commerce among the necessary elements of training. 


\section{Information Systems Design}

The other role, Information Brokers are prepared to do is to serve in large companies as information services expert. A special part of the corpus of knowledge needed to be successful in this role is the design of information systems. Their role is to connect clients and technical staff.

\section{Content of the Course "Informing Processes and Models"}

The role, Informing Processes and Models (IPM) plays in the Information Brokerage major, is critical to achieve the objectives of the program. Understanding that informing as essential for the success of information related services, defines the frame of learning 1 objectives of all other courses in the major. The IPM is a unique course not only for our school. This course presents a comprehensive introduction to the informing as a scientific discipline, which is the major objectives of information systems (see Buckland, 1991, p. 10), and the phenomenon of informing systems, as the new quality level of information systems, as proposed by Cohen (1999). The students are introduced to variety of informing processes and models, which are still on research stage. The content of the course is organized around several topics:

\section{Phenomenon of Information and Different Aspects of Information}

This IPM course uses a relatively narrow definition of information, which addresses informing human. To great extent, this introduction is based on Buckland' concepts emphasizing that information is the know ledge obtained via communication. Fundamental concepts, such as data; communication; tacit and explicit know ledge; information as physical object served to transmit the message; relationship between belief and know ledge; the role of information to reduce uncertainty in decision making; process to obtain operational know ledge, are discussed.

Students are taken notice of the hierarchical structure of information creation - data, information, know ledge. Traditionally the established hierarchical nature of information suggests that data is a prerequisite for information, and information is a prerequisite for knowledge. It introduces to the students the confusion between basic concepts of data, information and knowledge and more importantly the relationship between them. We try to show the process of perceiving, observing, receiving information and gaining knowledge as a dynamic and circular process which does not have very clear inner boundaries. The accent is on how individuals acquire and interpret data, information and knowledge and their impact on what course of action they will undertake in collecting, managing and sharing these within the ir organization.

\section{Shannon's communication model}

This theme includes the theoretical basis of communication and definition of basic terms. The five fundamental elements of communication system are described: the source of information, encoder, communication channel, decoder, and receiver. The model is extended to detail introduction of the phases of acquiring information by the receiver. The phases of understanding, accepting and adopting of information are discussed to highlight the factors leading to failures in this process: noise, mistrust and misunderstanding.

\section{Information systems and informing systems}

The main goal of this topic is to introduce and define the term information system (IS) and commonly adopted terminology in this field as follow: 
- The basic information processes within IS: information collection, storage, retrieval and dissemination;

- The technology, people, and organizational components of an information system;

The students are introduced with the basic methods to define IS, what areas of knowledge IS includes and what areas of human activities use it. They are acquainted with the Cohen's evolutionary approach to defining IS and with a new conceptualization of IS. It is an introduction to Informing Science as a discipline.

\section{Informing framework: Cohen's model}

The students are presented the Cohen's schema of informing, based on Shannon's communication model. The two models are collated in three points:

- Information in Shannon's model is defined in terms of the receiver's level of unceainty, and in Cohen's model it is defined as that which reduces risk for the decision-maker.

- The Informing Science framework uses a "meta-approach" to modeling the ability to characterize such systems at many levels. Three such levels include the level at which actual informing occurs, the level at which new informing instances are created, and the level at which overall designs for such systems are specified.

- The inherent inter-relatedness of the components of informing systems: task, technology, structure and people.

\section{Categories of informing processes}

The two aspects of informing processes: cardinality ratio (one-to-one; one-to-many and many-tomany) and availability of feed-back are used to classify different categories of informing prosses.

\section{Quantitative measures of the success of an informing process}

The management requires measuring. Introducing students to models allowing quantitative measuring of the success of an informing process follows Christozov, Chukova, and Mateev (2006, 2007, 2008). These models emphasize the risk of misunderstanding based on information asymmetry.

\section{Universal conditions for effective informing}

The other aspect of failures in informing process - the trust - is discussed by following the concept of credibility, proposed by Gackowski (2006a, 2006b). Credibility as a term addresses the quality in received message from the point of view of the trust toward the sources of information. The primary and secondary factors affecting credibility are introduced - factors directly affecting credibility (variety of independent sources, source-specific credibility) and factors indirectly affecting credibility.

\section{Examples of informing processes}

Cases like e-commerce, CRM, training are introduced in the light of informing science. Particular attention is giving to instruments used to enhance the trust and learning, which reduce the risk of misinforming. Special attention is giving to warranty as a tool to share this risk. 


\section{Students' Learning Objectives and Outcome Assessment}

\section{Learning Objectives}

The fundamental role of this course in the Information Brokerage curricula is to introduce students, at a very early stage of their study, the basic concepts of informing science. Understanding the importance of every stage in the process of conveying a message to a client in a way to facilitate acquiring operational knowledge is critical in each and every later course, because the know ledge generated in those courses will be placed in the frame of the concepts of informing and will allow students to emphasize it from point of view of informing. In particular, after completing the course, students will be able to analyze critically every case, which includs transfer of information, according to the success of informing in its completeness - not only by de livering the message as it was composed by the senders, but also how the message is understood, accepted, adopted, and whether or not it generate correct, operational and not mis leading knowledge. Additionally, students will learn how to measure the risks associated with this process; and to prevent or reduce the risk by applying different techniques.

\section{Outcome Assessment}

Students' assessment outcomes are spread across the following categories of learning:

- Knowledge is to know specific facts, principles, etc.

- Comprehension is the ability to explain a point.

- Application is using known facts to solve problems.

- Analysis is the ability to break a product apart into its requis ite elements or logical components.

- Synthes is is the ability to create something new.

- Evaluation is the ability to judge quality.

Three form of assessing students' learning are used. The first two forms represent formal methods used to grade students in the course. The first form is a more or less standard test, examining how students are using basic terminology of informing science and how they understand and are able to interpret fundamental concepts. It addresses the first two levels of learning 1 - knowledge and comprehension. The basic components of the test are given in Table 1.

Table 1. Structure of the test

1. Explain how information is a key resource and know the characteristics of information. Demonstrate an understanding of relationships data, information and knowledge. Define the key terms: information, information system, MIS, AIS

2. Explain why know ledge of information systems is important for business professionals and identify functions of information systems. Define informing framework and informing system. Describe basic components of informing systems; differentiate between Cohen's model and Shannon's communication model. Provide examples of several major types of informing systems from your experiences with business organizations in the real world.

3. Understand that context is essential for informing process. Understand user psychology. 
4. Define universal conditions for effective informing.

5. Define credibility as information quality; analyze the primary and secondary factors affecting credibility. Understand the concepts misinforming and information asymmetry. Know the instruments used to reduce the risk of mis informing

6. Give examples to illustrate informing processes in electronic commerce and CRM.

7. Provide examples of real world informing systems. Illustrate that in an information system, people use hardware, software, data, and networks as resources to perform input, processing, output, storage, and control activities that transform data resources into information products.

The second form of assessment addresses students' ability to apply what they learn to solve problems - Evaluation, Analys is and Application. During the course, students have to analyze a particular, taken from the practice, case of an information system, in order to identif y the sources of risk, to assess the levels of risk for different categories of users; and, if applicable, to propose how the risk of misinforming can be evaluated. This case study emphasizes the causes and effects of failures in the informing process supported by the given information system.

The third form assesses how students apply what they have learned in this course across the curriculum. This form assess whether students are able to apply their knowledge in designing information systems, or it addresses the last level of learning - synthesis.

\section{Impact of the IPM Course on Students from Other Disciplines}

The course Informing processes and models is open, as an elective, to students from two of the other majors - the major of Information technology and the major of Information security. The main purpose of these two majors is design of information systems from two different aspects. The first one address mostly technological aspects of Information systems design and the second emphasizes the security of information in information systems.

The students from these two majors, who selected Informing processes and systems, proved to understand better the clients' needs and how information, de livered by an information system, serves in decision making and what are the qualities of the information systems essential in improving effectiveness of decision making based on information provided by the information systems. This understanding serves them while designing information systems to address not solely technical or security issues, but to look on this design from a broader perspective.

\section{Conclusion}

There are two major difficulties in designing and implementing the course:

From one side the course have to be offered on an early stage of curriculum. At this stage of their study students have problem to learn from heterogeneous materials. The lack of textbooks, and other written teaching materials, causes to use only research papers. This creates huge problems to students. Additional difficulty creates students inability to read complex English texts. Preparation of handouts is the only solution, but it takes a lot of time and efforts. The process of translating and adjusting materials to serve as reading in the course are still ongoing.

Another difficulty in teaching the course comes from lack of specially designed cases. The cases, developed for teaching Information Systems, do not provide suffic ient details to address inform- 
ing component as well as needed. Adjustment of cases and development of specially designed cases is the problem of the future.

Despite the problems, listed above, the experience obtained so far allows us to conclude that introducing the basic concepts of informing science as early as in the first year of study is a productive way to increase students' abilities to address clients' need in design of computerized information systems.

\section{References}

Buckalnd, M. (1991). Information and information systems. NY: Preager.

Christozov, D., Chukova, S., \& Mateev, P. (2006). A measure of risk caused by information as ymmetry in e-commerce. Journal of Issues in Informing Science and Information Technology, 3, 147-158. Retrieved fro $\mathrm{m}$ http://informingscience.org/proceedings/InSITE2006/IISITChri169.pdf

Christozov D., Chukova S., \& Mateev P. (2007). On the relationship between warranty and the risk of information asymmetry. Journal of Issues in Informing Science and Information Technology, 4, 235-249. Retrieved from http://proceedings.informingscience.org/InSITE2007/IISITv4p 235-249Chri295.pdf

Christozov D., Chukova S., \& Mateev P. (2008). Warranty and the risk of misinforming: Evaluation of the degree of acceptance. Issues in Informing Science and Information Technology, 5, 667-677. Retrieved fro $\mathrm{m}$ http://proceedings.informingscience.org/InSITE2008/IISITv5p 667-677Chris444.pdf

Christozov D., Denchev, S., Toleva-Stoimenova, S., \& Rasheva-Yordanova, K. (2008). Training information brokers: A curricu lu m model. Journal of Issues in Informing Science and Information Technology, 5, 87-94. Retrieved fro $\mathrm{m}$ http://proceedings.informingscience.org/InSITE2008/IISITv 5p087094Chris 441.pdf

Cohen, E. (1999). Reconceptualizing information systems as a field of the transdiscipline in forming science: From ugly duckling to swan. Journal of Computing and Information Technology, 7(3), 213-219. Retrieved from http://inform.nu/WhatsIS.htm

Gackowski Z. J. (2006a) Quality of Informing: Credibility. Provisional Model of Functional Dependencies, Proceedings of the 2006 Informing Science and IT Education (InSITE) Conference, 2006. Retrieved fro $\mathrm{m}$ http://proceedings.informingscience.org/InSITE2006/Proc Gack194.pdf

Gackowski, Z. J. (2006b). Quality of informing: Disinformation and bias - Philosophical background and roots. Joumal of Issues in Informing Science and Information Technology, 3, 731-744. Retrieved from $\mathrm{http} / / /$ informingscience.org/proceedings/InSITE2006/IISITZbig250.pdf

Gackowski, Z. J (2007) Informing as a discipline: An in itial proposal. Proceedings of the 2007 Informing Science and IT Education Joint Conference, p.187-208. Ljubljana, June 2007. Retrieved from http://proceedings.informingscience.org/InSITE2007/InSITE07p 187-208Gack346.pdf

\section{Biographies}

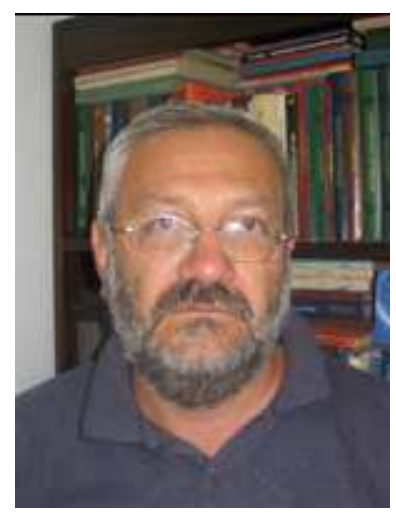

Dimitar Christozov is a Professor of Computer Science at the American University in Bulgaria, Blagoevgrad 2700, Bulgaria since 1993. He has more than 25 years of experience in areas as computer science, quality management and information systems. He graduated Mathematics from Sofia University "St. Kliment Ohridski”" in 1979. He completed his PhD thesis "Computer Aided Evaluation of Machine Reliability" in 1986. In ICTT "Informa" (1986-1993) Dr. Christozov was involved in establishing the national information network for technology transfer and research in the areas of technologies assessment, integral quality measures and information systems for quality management. 
In these areas he was recognized as one of the leading experts in Bulgaria. Professor Christozov has more than 50 publications as separate volume, journal papers and papers in refereed proceedings. He is a founding member of Informing Science Institute and chair of Bulgarian Informing Science Society; and member of the Bulgarian Statistical Society.

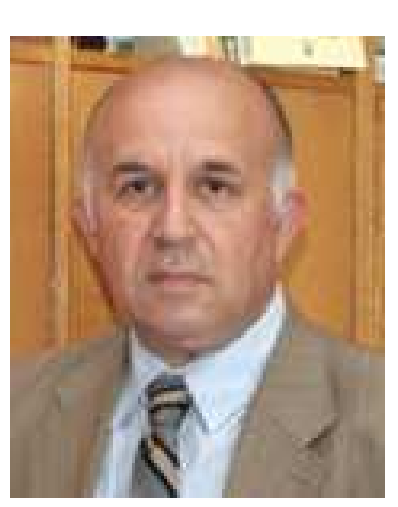

Stoyan Denchev, a Professor of Economics, is a Rector of State University of Library Studies and Information Technologies, Sofia. He graduated at Sofia University "St. Kliment Ohridski”' in 1978, MS, Public Administration and Computer Science. From 1978 to 1986 he worked at the Central Machine-building Institute. In ICTT "Informa" (1986 to 1988) he filled the positions of Director of Science and then Vice Director-General. He obtained his $\mathrm{PhD}$ in Computers and Information Systems in 1983 and his Doctor of Economics degree in 2004. In 2005 he was elected as a Professor. In 1988/9 he was a Visiting Professor at University of California, Berkeley. His research fields are: System Analys is, Computer Sciences, Information Technologies, Information Systems, Information Security, Public Administration and

Human Resource Management. He has more than 150 publications. From 2006 he is a chairman of the Union of Bulgarian Libraries.

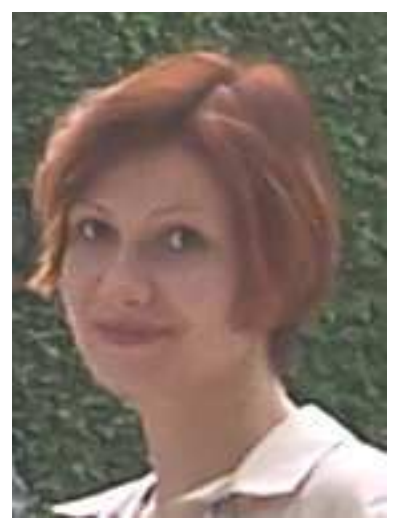

Stefka Toleva-Stoimenova is a Senior Assistant Professor of Mathematics and Informatics at the State University of Library Studies and Information Technologies, Sof ia, Tzarigradsko shosse Blvd. 119, Bulgaria 1784, s_toleva@yahoo.com. She has obtained her MSc degree in Industrial Automation from the Faculty of Automation and System Design, Technical University - Sofia. Her main research interests are in the field of Automation and Informatics. She is currently researching to obtain his $\mathrm{PhD}$ degree on Informing Science and Automated Information Systems. She is a member of Bulgarian Informing Science Society 